khuẩn trước khi dùng", do không thu thập được đầy đủ thông tin về tình trạng bệnh nhẩn nên chưa đánh giá được tính phù hợp của kháng sinh trong các trường hợp này.

Đối với nhóm "Không có chẩn đoán nhiễm khuẩn và không có dấu hiệu nhiễm khuẩn trước khi dùng" (59 bệnh nhân), trong đó ghi nhận được 23 trường hợp mổ lấy thai. Trong mổ lấy thai, theo khuyến cáo của ACOG (Hiệp hội sản phụ Mỹ) kháng sinh được dùng 1 liều duy nhất đối với ca mổ không biến chứng vừa có hiệu quả tương tự chế độ dùng đa liều vừa giúp giảm chi phí, độc tính và kháng thuốc [3]. Trong nghiên cứu, cefuroxim được sử dụng trong mổ với 1 liều duy nhất và sau mổ với chế độ liều như điều trị nhiễm khuẩn. Do không thu thập được đầy đủ thông tin về yếu tố nguy cơ nhiêm khuẩn trong phẫu thuật nên chưa thể bàn luận về tính phù hợp của phác đồ kháng sinh này. Ngoài các bệnh nhân mổ lấy thai, cũng do không thu thập được đầy đủ thông tin về tình trạng của nhóm bệnh nhân còn lại nên chưa thể đánh giá được sự phù hợp của các phác đồ kháng sinh đã sử dụng.

Trong mẫu nghiên cứu, cefuroxim được dùng theo đường tiêm tĩnh mạch với liều 750 - 1500 $\mathrm{mg} \times 2$ lần/ngày. Tuy nhiên, cefuroxim hầu như không có trong các khuyến cáo điều trị nhiễm khuẩn sản phụ khoa. Theo thông tin sản phẩm của biệt dược gốc Zinacef, chế độ liều trong điều trị các bệnh lý nhiễm khuẩn là $750-1500 \mathrm{mg} \times$ $3-4$ lần/ngày [7]. Như vậy có sự khác biệt giữa số lần dùng/ngày thực tế và thông tin sản phẩm.

\section{KẾT LUÂ̂N}

Nghiên cứu cho thấy mức tiêu thụ cefuroxim đứng hàng thứ 4 tại khoa Sản nhiễm khuẩn năm 2019. Tuy nhiên, đa số các phác đồ cefuroxim được sử dụng không có trong các hướng dẫn điều trị. Có sự khác biệt về liều dùng thực tế so với khuyến cáo của biệt dược gốc Zinacef. Cần có thêm các nghiên cứu đánh giá sử dụng kháng sinh với số lượng kết quả vi sinh lớn hơn để có những bàn luận rõ hơn về sự phù hợp của các phác đồ kháng sinh với tình hình đề kháng của vi khuẩn gây bệnh tại đây.

TÀI LIẸU THAM KHẢO

1. Bệnh viên Từ Dũ (2019), "Phác đồ điều trị sản phụ khoa", pp.

2. Nguyến Thu Nga (2019), "Khảo sát tình hình tiêu thu kháng sinh và đề kháng kháng sinh của các vi khuẩn gây bệnh phân lập được tại Bênh viện phụ sản Trung ương", Khóa luận tốt nighiệp dược sĩ, Đại học Dược Hà Nội, pp.

3. ACOG (2018), "Practice Bulletin No.199: Use of Prophylactic Antibiotics in Labor and Delivery", Obstetrics \& Gynecology, 132(3), pp. e103-e119.

4. Antimicrobial Therapy Inc. (2016), The Sanford Guide To Antimicrobial Therapy, pp. 6-78.

5. CDC (2015), "Pelvic Inflammatory Disease, Sexually Transmitted Diseases Treatment Guidelines", pp.

6. Gilles R. G. Monif David A. Baker (2008), Infectious Diseases In Obstetrics And Gynecology, pp. 17.

7. GlaxoSmithKline UK, Summary of Product Characteristics: Zinacef. 2020, Electronic Medicines Compendium (EMC).

\title{
VAI TRÒ CộNG HƯỞNG TỪ 3 TESLA TRONG ĐộNG KINH THÙY THÁI DƯƠNG
}

\section{Lê Viết Thắng*, Nguyễn Thanh Lâm*, Đào Nguyễn Trung Luân*, Nguyễn Đức Vũ*, Phạm Thanh Bình*, Nguyễn Minh Anh*}

\section{TÓM TẮT}

Mục tiêu. Mô tả đặc điểm hình ảnh trên cộng hưởng từ (MRI: magnetic resonance imaging) và đánh giá vai trò MRI sọ não 3 Tesla trong chẩn đoán nguyên nhân/vị tí/bản chất tổn thương trong động kinh thùy thái dương. Phương pháp. Tất cả bệnh nhân được chẩn đoán xác định động kinh thùy thái dương và điện não đồ có chụp cộng hưởng từ 3 Tesla.

\footnotetext{
*Bênh viện Đại Học Y Dược TP. Hồ Chí Minh Chịu trách nhiệm chính: Lê Viết Thắng Email: Drlevietthang@ump.edu.vn Ngày nhận bài: 16.11.2020 Ngày phản biện khoa học: 30.12 .2020 Ngày duyệt bài: 15.01.2021
}

Nghiên cứu mô tả cắt ngang, từ 01/01/2016 đến $31 / 12 / 2020$, khoa Ngoai Thần Kinh bệnh viện Đai hoc Y Dược TP Hồ Chí Minh. Kết quả. Có 36 nữ và 20 nam, độ tuổi trung bình là 39,2 tuổi. Tất cả bênh nhân đều được bác sĩ thân kinh chẩn đoán động kinh thùy thái dưởng, kèm điện não đồ. Trong 56 trường hợp có 10/56 trường hợp xơ hóa hải mã, 1/56 trường hợp loạn sản vỏ não khu trú, 11/56 trướng hợp u mạch máu dạng hang, 3/56 trường hợp dị dạng mạch máu não, 8/56 trường hợp u màng não, 16/56 trường hợp u sao bào, và 7/56 trường hợp khác. Trong 7 trường hợp khác, giải phẫu bệnh sau mổ giúp phân loại cụ thể: u quái thượng bì, u hạch thần kinh đệm, u ngoại bì thân kinh nghịch sản phôi... Kết luận. Cộng hưởng từ sọ não 3 Tesla là công cụ quan trọng, cân thiêtt trong chẩn đoán động kinh thùy thái dương có sang 
thương. MRI sọ não là một khâu quan trọng trong lượng giá trước phẫu thuật những bệnh nhân động kinh thùy thái dương có thương tổn não.

Tư khóa: cộng hưởng từ 3 Tesla, động kinh thùy thái dương.

\section{SUMMARY}

\section{TESLA MAGNETIC RESONANCE IMAGING FEATURES IN LESIONAL TEMPORAL LOBE EPILEPSY}

Objective of the study: To determine the usefulness and characteristics of 3 Tesla magnetic resonance imaging in lesional temporal lobe epilepsy. Subjects and research methods: Patients were diagnosed temporal lobe epilepsy, presurgical evaluation tool based on semiology, electroencephalography and brain MRI with epilepsy protocol. This is a cross-sectional study, in Neurosurgery Department in Ho Chi Minh City University Medical Center. The duration was sixty months from $1^{\text {st }}$ Janurary 2016 to $31^{\text {th }}$ December 2020. Results: 36 female: 20 male. Median age: 39,2 year-old. All patients are diagnosed temporal lobe epilepsy by neurologists (semiology and EEG). 56 leisonal temporal lobe epilepsy patients on MRI have: hippocampal sclerosis $(n=10)$, focal cortical dysplasia $(\mathrm{n}=1)$, cavernoma $(\mathrm{n}=11)$, arterioveinous malformation $(n=3)$, meningioma $(n=8)$, astrocytoma $(n=16)$, and others $(n=7)$. Anatomical pathology details show to be what other cases: tetratoma, gangliomglioma, dysembryoplastic neuroepithelial tumor,... Conclusions: 3 Tesla MRI is a essential tool to diagnose for lesional temporal lobe epilepsy. MRI is one of the most important parts in the presurgical evaluation for temporal lobe epilepsy.

Key Words: 3 TESLA magnetic resonance imaging, temporal lobe epilepsy.

\section{I. ĐĂTT VẤN ĐỀ}

Động kinh là vấn đề sức khỏe cộng đồng, ảnh hưởng trên 50 triệu người trên toàn thế giới. Động kinh là một nhóm bệnh mạn tính của hệ thần kinh. Bản chất của động kinh là sự phóng lực bất thường, đột ngột, quá mức của các tế bào thần kinh và được biểu hiện trên lâm sàng với các triệu chứng như cơn vận động, cảm giác, giác quan hay tâm thần. Theo Wiebe $S$. và cộng sự, động kinh chiếm tỉ lệ $0,45-1,15 \%$ dân số, trong đó có $8,52-15,3 \%$ là động kinh cục bộ phức tạp [7].

Động kinh đòi hỏi phải điều trị thuốc lâu dài, khoảng 30\% bệnh nhân không đáp ứng với điêuu trị nội khoa. Phẫu thuật động kinh có thể là phương pháp điều trị thay thế trong những trường hợp này [5], [7]. Cộng hưởng từ là công cụ hiệu quả giúp đánh giá bệnh nhân trước phẫu thuật. Gần đây, cộng hưởng từ 3 Tesla đã giúp phát hiện nhiều thương tổn não hơn trong động kinh. Mục tiêu của nghiên cứu này nhằm đánh giá vai trò và đặc điểm hình ảnh những thương tổn thường gặp trên cộng hưởng từ sọ não 3 Tesla trong động kinh thùy thái dương.

\section{II. ĐỐI TƯƠ'NG VÀ PHƯƠNG PHÁP NGHIÊN CỨU}

Tiêu chuẩn chon bênh: Tất cả bênh nhân được chẩn đoán xác định động kinh thùy thái dương trên lâm sàng và điện não đồ chụp cộng hưởng từ 3 Tesla có sang thương tại bệnh viện Đại học Y Dược thành phố Hồ Chí Minh từ 01/01/2016 đến 31/12/2020.

Tiêu chuẩn loại trừ

- Bệnh về tâm thần kinh nặng: trầm cảm, tâm thần phân liệt, rối loạn lưỡng cực,...

- Nhiều vùng sinh động kinh rải rác hai bán cầu

- Bệnh thần kinh tiến triển: tai biến mạch máu nã̃o, viêm não,...

Nghiên cứu mô tả cắt ngang. Số liệu thu thâpp tại khoa Ngoại Thần Kinh bệnh viện ĐHYD TPHCM từ 01/01/2016 đến 31/12/2020. Thu thâp các thông số về hành chánh (ho và tên, tuổi tác, giới tính,...), lâm sàng động kinh thùy thái dương được bác sĩ thần kinh chuyên về động kinh chẩn đoán, kết quả cộng hưởng từ sọ nã̃o và so sánh với kết quả giải phấu thuật (nếu có). Thống kê bằng phần mềm SPSS 20.0.

Tất cả bệnh nhân chụp MRI 3T theo quy trình bệnh động kinh khoa chẩn đoán hình ảnh, bệnh viện Đại học Y dược TP. Hồ Chí Minh. MRI thường quy ở bệnh nhân động kinh bao gồm hình T2 (T2 relaxometry) hướng trục; hình T2 spin-echo vuông góc với trục dài của hồi hải mã; hình FLAIR vuông góc với trục dài của hồi hải mã; hình T2 gradient-echo theo trục hoăc hình SWI; hình FSPGR-IR có trọng số T1 và kỹ thuật đo bề dầy chất xám vỏ não trong loạn sản vỏ não khu trú. Bên canh những chuối xung thường dùng trên MRI, một qui trình thống nhất trong động kinh được sử dụng: T1WI bao gồm 3D sequence: MPR/FSPGR(Fast spoiled gradient echo)/MPRAGE, T2WI: axial/coronal lát cắt 1$3 \mathrm{~mm}$, FLAIR/FLAIR CUBE: axial/coronal (vuông góc trục hải mã) lát cắt $1-3 \mathrm{~mm}$. Việc dùng thuốc cản quang được thực hiện tùy thuộc vào tình trạng lâm sàng, đặc biệt để đánh giá khối u cùng với các kỹ thuật tiên tiến hơn trong một số trường hợp được chọn.

\section{KẾT QUẢ NGHIÊN CỨU}

Có 36 nữ và 20 nam tham gia trong nghiên cứu, độ tuổi trung bình là 39,2 tuổi. Tất cả bệnh nhân đều được. Trong 56 trường hợp chụp cộng hưởng từ 3 Tesla có 10/56 trường hợp xơ hóa hải mã, 2/56 trường hợp loạn sản vó não khu trú, 11/56 trường hợp u mạch máu dạng hang, 
3/56 trường hợp dị dạng mạch máu não, 8/56 trường hợp u màng não, 16/56 trường hợp u sao bào, và $6 / 56$ trường hợp khác.

\section{Số ca}

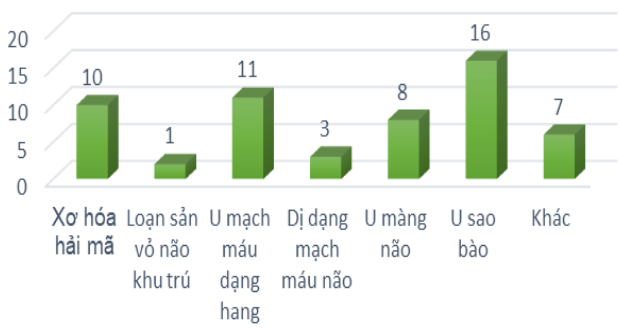

Biểu đồ 1: Sang thương trên cộng hưởng từ bệnh nhân động kinh thùy thái dương

Tất cả bệnh nhân được phẫu thuật điều trị động kinh thùy thái dương, có kết quả giải phẫu bệnh phân loại theo bảng 1 .

Bảng 1: Liên quan cộng hưởng từ trước mổ và giải phẫu bệnh

\begin{tabular}{|c|c|c|c|}
\hline $\begin{array}{l}\text { Cộng hưởng } \\
\text { tư̆ }\end{array}$ & $\begin{array}{c}\begin{array}{c}\text { Số } \\
\text { trường } \\
\text { hợp }\end{array} \\
\end{array}$ & $\begin{array}{c}\text { Giải phẫu } \\
\text { bệnh lý }\end{array}$ & $\begin{array}{c}\text { Số } \\
\text { trường } \\
\text { hợp }\end{array}$ \\
\hline Xơ hóa hải mã & 10 & $\begin{array}{c}\text { Xơ hóa hải } \\
\text { mã }\end{array}$ & 10 \\
\hline Bình thường & 1 & $\begin{array}{l}\text { Loạn sản vỏ } \\
\text { não khu trú }\end{array}$ & 1 \\
\hline $\begin{array}{l}\text { U mạch máu } \\
\text { dạng hang }\end{array}$ & 11 & $\begin{array}{l}\text { U mạch máu } \\
\text { dạng hang }\end{array}$ & 11 \\
\hline $\begin{array}{l}\text { Dị dạng mạch } \\
\text { máu não }\end{array}$ & 3 & $\begin{array}{l}\text { Dị dạng mạch } \\
\text { máu não }\end{array}$ & 3 \\
\hline U màng não & 8 & U màng não & 8 \\
\hline U sao bào & 16 & U sao bào & 16 \\
\hline $\begin{array}{l}\text { U thần kinh đệm } \\
\text { độ ác thấp }\end{array}$ & 3 & $\begin{array}{l}\text { U sao bào độ } 1 \\
\text { Ganglioglioma }\end{array}$ & $\begin{array}{l}1 \\
2\end{array}$ \\
\hline DNET & 1 & DNET & 1 \\
\hline $\begin{array}{l}\text { U quái thượng bì } \\
\text { U ngoài trục }\end{array}$ & $\begin{array}{l}2 \\
1\end{array}$ & $\begin{array}{c}\text { U quái } \\
\text { thượng bì }\end{array}$ & 3 \\
\hline Tống cộng & 56 & & 56 \\
\hline
\end{tabular}

Qua bảng kết quả so sánh cộng hưởng từ trước phẫu thuật và kết quả giải phẫu bệnh, hầu hết những trường hợp động kinh thùy thái dương chẩn đoán trên cộng hưởng từ phù hợp với kết quả giải phẫu bệnh sau phẫu thuật. Có $1 / 56$ trường hợp động kinh thùy thái dương không phát hiện trên cộng hưởng từ 3T, chiếm tỉ lệ 1,8\%. Có $4 / 56$ trường hợp MRI 3T chỉ phát hiện tổn thương thùy thái dương, chưa gợi ý chẩn đoán, chiếm tỉ lệ $7,1 \%$.

\section{BÀN LUÂ̂N}

Chúng tôi tổng kết những thương tổn thường gặp trên cộng hưởng từ $3 T$ trong động kinh thùy thái dương. Đây là nghiên cứu mô tả cắt ngang kết quả cộng hưởng từ và kết quả giải phẫu bệnh của bệnh nhân động kinh thùy thái dương, đa số gặp nữ nhiều hơn nam, độ tuổi trung bình 39,2. Với độ nhạy và độ đặc hiệu cao của cộng hưởng từ $3 T$ trong báo cáo này, chúng tôi bàn luân thêm về những sang thương khó chẩn đoán trển MRI như loạn sản vỏ não khu trú, xơ hóa hải mã, u hạch thần kinh đệm, u ngoại bì thần kinh nghịch sản phôi,...

Loan sản vỏ não khu trú: Dị tật phát triển vỏ não chiếm $10-50 \%$ tổng số ca bệnh động kinh ở trẻ em và $4-25 \%$ tổng số ca bệnh ở người lớn. Tuy nhiên, dị tật phát triển vỏ não thường gặp nhất ở những bệnh nhân này là loạn sản vỏ não khu trú. Các phát hiện MRI được đánh giá tốt nhất ở mức 3T bao gồm dày cục bộ vỏ não, thay đổi hình thái bề mặt, làm mờ điểm nối chất xám với chất trắng, tăng cường độ T2 và FLAIR của chất xám và chất trẳng và các dải cường độ tín hiệu bất thường từ vỏ não đến não thất bên [2]. Trong nghiên cứu của chúng tôi, MRI 1.5T tiêu chuẩn không có protocol động kinh ở các trung tâm không chuyên khoa không phát hiện được tổn thương trong đó MRI 3T phát hiện được tổn thương động kinh rõ ràng. Các phát hiện tương tự đã được báo cáo trong các nghiên cứu trước đầy. Trong một nghiên cứu tiền cứu khác được thực hiện ở người lớn, chứng minh rằng trong gần $60 \%$ trường hợp, chụp $M R I$ thông thường không có phương pháp diễn giải chuẩn hóa của bác sĩ thần kinh không phát hiện được tổn thương cấu trúc [2]. Nghiên cứu của chúng tôi cho thấy rằng loạn sản vỏ não khu trú cũng có thể ít bị bỏ sót với MRI 3T, có thể được chuyển hóa ở độ phân giải hình ảnh cao hơn, dẫn đến khả năng loại bỏ tốt hơn.

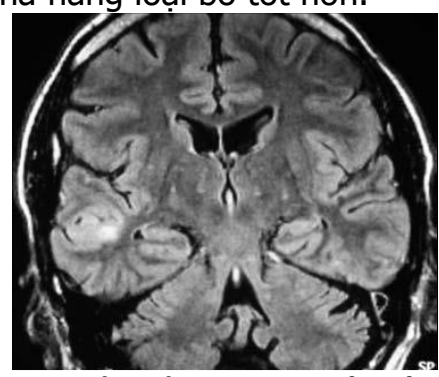

Hình 1: Loạn sản vỏ não khu trú thái dương phải BN: Đặng Công K.

Xơ hóa hải mã. Loại tổn thương thứ hai được phát hiện trong nghiên cứu của chúng tôi là xơ hóa hải mã. Xơ hóa hải mã đặc trưng bởi sự mất tế bào nơron và thần kinh đệm, là nguyên nhân thường gặp nhất trong động kinh thùy thái dương kháng thuốc. Lát cắt qua mặt 
phẳng trán doc theo chiều dài hải mã là cách tiếp cận tốt nhất phát hiện xơ hóa hải mã, tăng đậm độ trên $T 2 W$ và teo hải mã. Một phương pháp khác giúp chẩn đoán xơ hóa hải mã là đo thể tích đầu hải mã, độ nhạy $92 \%$ và độ dặc hiệu $100 \%$. Ngoài ra, chúng ta còn có thể thấy tăng tính hiệu trên T2W ờ thùy thái dương trước, teo trụ vòm não, thể vú và hồi canh hải mã. Việc đo kích thước hồi hải mã và thể tích đầu hải mã rất hữu dụng [4].

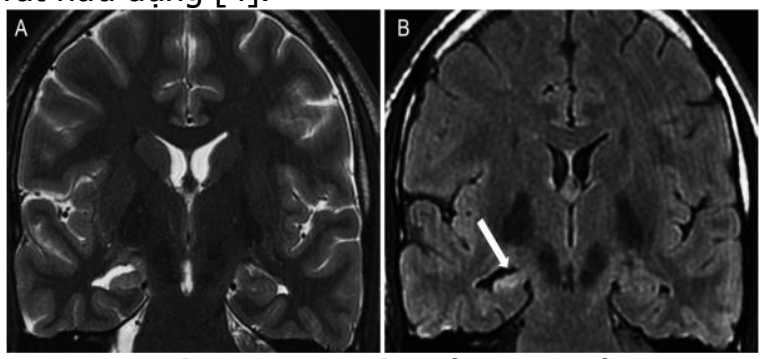

Hình 2: Xơ hóa hải mã phải

$\mathrm{BN}$ : Nguyễn Hoàng Quốc $\mathrm{H}$.

Tổn thương tân sinh. Tôn thương tân sinh thường gặp ở thùy thái dương là u tế bào thần kinh đệm, u hạch thần kinh đệm, u ngoại bì thần kinh nghịch sản phôi thường được xem như dị dang bất thường vỏ não thứ phát trong quá trình biêt hóa tế bào mầm. Những tổn thương tân sinh này thường gây động kinh kháng thuốc.

U thần kinh biểu mô nghịch sản phôi là một loại u thần kinh đệm, lành tính, xếp loại I theo WHO, phát sinh từ chất xám vỏ não, thường đi kèm với loạn sản vỏ não ( $80 \%$ các trường hợp). DNET thường là tổn thương sinh động kinh, đặc biệt trong thùy thái dương. Cộng hưởng từ ghi nhận tổn thương vỏ não, không phù xung quanh, giảm đậm độ trên chuỗi xung T1W, có thể bắt cản quang vùng nhân (khoảng 20-30\% các trường hợp), tăng đậm độ trên T2W, có hình ảnh can-xi hóa bên trong, có dấu hiệu "gọng kính" trên FLAIR, không hạn chế khuếch tán trên DWI [1], [2].

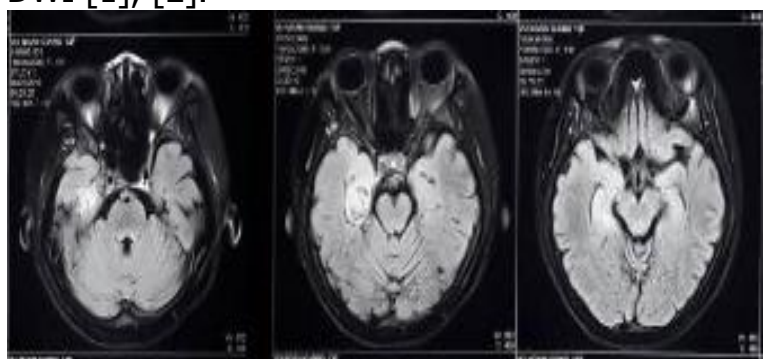

Hình 3: Cộng hưởng từ trên người bệnh có thương tổn não DNET - BN: Bùi Thi T.

U hạch thần kinh đệm là loại u ít gặp, khoảng 2\% u não, thường lành tính. U hạch thần kinh đêm có đặc đểm đa dạng trên công hưởng từ. U là tổ chức đặc đồng nhất và giảm tín đậm độ trên $T 1 W$, vùng tổ chức đặc có thể bắt thuốc cản từ, tăng đậm độ trên $T 2 W$, phù nhe quanh u trên FLAIR, có thể can-xi hóa trong lòng $u$ [1]. Chẩn đoán phân biệt với DNET, u độ ác thấp,...

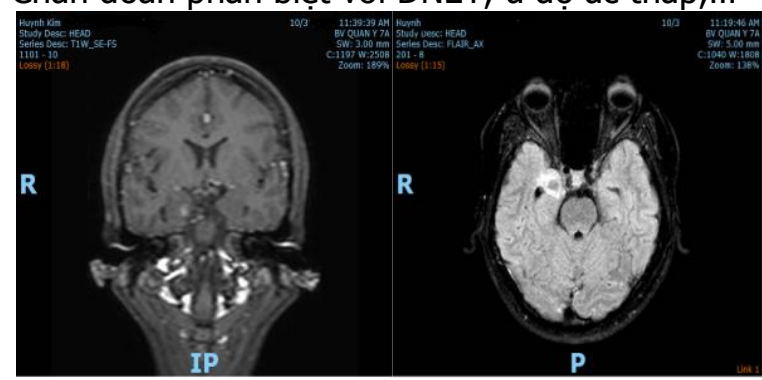

Hình 4: U độ ác thấp trên phim cộng hưởng từ $B N$ : Huỳnh Kim $T$.

Dị dạng mach máu não. U mạch máu dạng hang thường liên quan đến động kinh cục bộ kháng thuốc, và phẫu thuật cắt bỏ thích hợp trong trường hợp tổn thương duy nhất. $U$ mach máu dang hang được phát hiện tốt nhất bằng cách sử dung MRI. Bốn giai đoạn xuất huyết khác biệt được mô tả. Tổn thương loại 1 tương ứng với xuất huyết bán cấp và xuất hiện tăng tín hiệu T1 nhưng tăng cao hoặc giảm tín hiệu hình T2. Tổn thương loại 2 có một lõi lưới phức hợp được phân định rõ̃ ràng với cường độ tín hiệu hỗn hợp biểu thị nhiều đợt xuất huyết ở các độ tuổi khác nhau, và một vành hemosiderin hoàn toàn đã được ghi nhân trên hình T2. Tổn thương loại 3 là giảm tín hiệu trên T1, T2. Cuối cùng, các tổn thương loai 4 chỉ được quan sát bằng cách sử dụng chuỗi phản xạ gradient hoặc SWI như là các vùng giảm tín hiệu [2], [4].

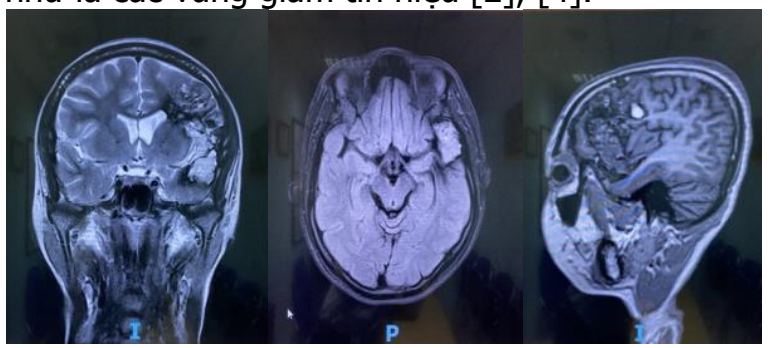

Hình 5: U mạch máu dạng hang có giả phinh trong u

BN: Nguyễn Thị Vân T.

MRI là một trong phương pháp có giá trị nhất giúp định vị thương tổn gây động kinh trước phẩu thuât. Những kỹ thuật tiến bộ đo kích thước hồi hải mã, bề dầy vỏ não,...đã góp phân giúp chẩn đoán vị trí, bản chất và nguyên nhân tổn thương chính xác góp phần quan trọng trong điều trị bệnh nhân [1], [2], [3], [4]. 


\section{KẾT LUÂN}

Cộng hưởng từ so não 3 Tesla là công cu quan trọng, cần thiết trong chẩn đoán động kinh thùy thái dương. MRI sọ não giúp lượng giá trước phẫu thuật những bệnh nhân động kinh thùy thái dương có những thương tổn não cần phẫu thuật.

\section{KHUYẾN NGH!}

Với sự phát triển không ngừng của khoa học kỹ thuật hiện đại ứng dụng vào y học, cộng hưởng từ 3T đã chứng minh vai trò quan trọng trong chẩn đoán bệnh thần kinh, đặc biệt là bản chất, vị trí tổn thương trong động kinh thùy thái dương. Do vây, để người bênh được điều trị tốt nhất, thầy thuốc ngoại thần kinh nên cân nhắc cho người bệnh động kinh thùy thái dương chụp cộng hưởng từ 3ị giúp xác định nguyên nhẩn gây bệnh, từ đó có phương pháp điều trị tối ưu cho bệnh nhân.

\section{Các từ viết tắt}

DNET: Dysembryoplastic Neuroepithelial Tumor MRI: Magnetic Resonance Imaging

WHO: World Health Organization; 3T: 3 Tesla

\section{TÀI LIẸU THAM KHẢO}

1. Bartoli A., Vulliemoz S., Haller S., Schaller K., and Seeck M. (2012)," Imaging techniques for presurgical evaluation of temporal lobe epilepsy", Imaging Medicine, Volume 4(4), pp. 443-459.

2. Casciato S., Picardi A., D'Aniello A., et al (2017), "Temporal pole abnormalities detected by $3 \mathrm{~T}$ MRI in temporal lobe epilepsy due to hippocampal sclerosis: No influence on seizure outcome after surgery", Seizure, Volume 48, p. 74-78.

3. Ercan K., Gunbey H. P., Bilir E., Zan E., and Arslan H. (2016), "Comparative lateralizing ability of multimodality MRI in temporal lobe epilepsy", Hindawi publishing corporation, Volume 2016, Article ID 5923243, 9 pages.

4. Liao C., Wang K., Cao X., et al (2018), "Detection of lesions in mesial temporal lobe epilepsy by using MR fingerprinting. Original research", Radiology 2018; 288, pp. 804-812.

5. Võ Văn Nho, Võ Tấn Sơn (2013), "Động Kinh", Phẫu thuật thân kinh, Nhà xuất bản Y Học, tr. 657-676.

6. Võ Văn Nho, Võ Tấn Sơn (2013), "Ứng dụng cộng hưởng từ cao cấp trong u não", Phâuu thuật thân kinh, Nhà xuất bản Y Học, tr. 695-724.

7. Wiebe S., Blume W. T., Girvin J. P., Eliasziw M. (2001), " Effective and efficiency of surgery for temporal lobe epilepsy study group", N Eng J Med; 345(5), pp. 311-31

\section{ĐÁNH GIÁ MộT Số BIẾN CHỨNG VÀ TÁC DƯNG KHÔNG MONG MUỐN DO DÙNG NICARDIPIN ĐỂ KIỂM SOÁT HUYẾT ÁP Ở BÊ̂NH NHÂN TIỀN SẢN GIÂTT GÂY MÊ NộI KHÍ QUẢN MỔ LẤY THAI}

\section{TÓM TẮT}

Mục tiêu:. So sánh các biến chứng và một số tác dụng không mong muốn của nhóm can thiệp tiêm Nicardipin trước khi đặt nội khí quản và nhóm không can thiệp để kiểm soát huyết áp trong nghiên cứu. Phương pháp nghiên cứu: Nghiên cứu lâm sàng có đối chứng trên bệnh nhân tiền sản giật có tăng huyết áp độ 2 có chỉ định gây mê nội khí quản để lấy thai tại Bệnh viện Phụ sản trung ương từ tháng 4 đến tháng 9 năm 2019. Kết quả nghiên cứu: Nhóm có can thiệp nicardipin mạch tăng từ $86.8 \pm 7.6$ lần/phút trước tiêm lên $102.7 \pm 9.8 /$ phút tai thời điểm 1 phút sau tiêm Nicardipin (khoảng 18\%) và tăng cao nhất lên tới 106.5 × 10.0 lần/phút (khoảng 19\%) lúc đăt NKQ, sau đó lại giảm xuống mức an toàn (dưới 100 lần/phút).

*Bệnh viện phụ sản Trung ương,

* Đại hoc Y Hà Nôii,

***Bênh viện Việt Đúc

Chịu trách nhiệm chính: Bạch Minh Thu

Email: bachminhthu@gmail.com

Ngày nhận bài: 18.11 .2020

Ngày phản biên khoa học: 4.01.2021

Ngày duyệt bằi: 14.01 .2021
Bạch Minh Thu*, Công Quyết Thắng**, Luu Quang Thùy***

Các tác dụng không mong muốn khác như nôn và buôn nôn, đau đâu, thiểu niệu, chảy máu.. ở 2 nhóm là tương đương nhau. Kết luấn: Sử dung nicardipin có thể làm mạch nhanh hơn nhưng vấn an toàn để dùng cho việc kiểm soát huyết áp ở những bênh nhân tiền sản giật được gây mê nội khí quản để mổ lấy thai. Các tác dụng không mong muốn khác cũng như sự ảnh hưởng đến thai nhi khi dùng nicardipin ở 2 nhóm là như nhau

Tư khóa: Nicardipin, tiền sản giật (TSG), mổ lấy thai, Tác dụng không mong muốn

\section{SUMMARY \\ EVALUATE THE COMPLICATIONS AND SIDE EFFECTS OF USSING NICARDIPINE FOR BLOOD PRESSURE CONTROL IN GENERAL ANESTHESIA FOR PRE-ECLAMPSIA REQUIRED CESAREAN SECTION}

Objectives:. To compare the complications and some side effects of intervention group with nicardipine injection before tracheal intubation versus control group in blood pressure control. Method: Randomized controlled trial in pre-eclampsia patients with stage 2 hypertension having indication of 